\title{
Feasibility Study of Synthetic Oil Based Nanofluids for Use in Thermal Oil Heaters
}

\author{
Ian Mullett \\ Faculty of Engineering and Applied Science, Memorial \\ University of Newfoundland, St. John's, Canada \\ ihrm55@mun.ca \\ Xili Duan \\ Faculty of Engineering and Applied Science, Memorial \\ University of Newfoundland, St. John's, Canada \\ xduan@mun.ca
}

\author{
Zongming Wang \\ College of Chemical Engineering, China University of \\ Petroleum, Qingdao, Shandong, China \\ wzmcc@upc.edu.cn \\ Yishan Li \\ Shandong Special Equipment Inspection Institute Co. Ltd, \\ Jinan, Shandong, China \\ liyishan@sei.sd.cn
}

\begin{abstract}
Thermal oil heaters can be considered as an alternative to steam boilers for process heating use. Instead of boiling water, thermal oil heaters use heat transfer oils with high boiling points which allows operation at low pressures. To increase thermal oil heater efficiency, a nanofluid consisting of a common heat transfer oil, the synthetic TH66, and copper nanoparticles has been proposed. Based on existing correlations for nanofluids, a figure of merit (FOM) was created to evaluate heat transfer performance while factoring in pumping power increases. A maximum FOM increase of $13 \%$ was found for a thermal oil heater using the nanofluid when compared to one that uses the base fluid oil.
\end{abstract}

Keywords- Thermal Oil Heater; Nanofluid; Heat Transfer; Feasibility Study.

\section{INTRODUCTION}

Traditionally, water boilers are used to provide steam or heat for residential or industrial process applications. To reach the high temperatures required for process applications, high pressure steam is required. In lieu of using a steam boiler, a thermal oil heater is used to heat the oil. In general, the heaters are gas fired with a burner located in the center of a helical coil. The hot exhaust gases generally travel several passes over the coil to heat the thermal oil. Heat transfer fluids such as thermal oils, can be used as a substitute for steam and can reach much higher temperatures at minimal system pressures. The use of thermal oils also eliminates freezing and corrosion concerns, and no water treatment is necessary. Synthetic heat transfer oils provide higher stability at elevated temperatures, and offer higher thermal conductivity than other heat transfer fluids $(0.1$

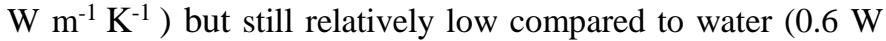
$\mathrm{m}^{-1} \mathrm{~K}^{-1}$ at room temperature).

In 1995, Choi published a paper showing the enhancement of thermal physical properties of a basefluid with dispersed nanoparticles, referred to as a nanofluid [1]. Since then, many papers have been published on the topic of nanofluids, mainly showing the thermal conductivity enhancement of water based nanofluids. Although the quantity of research is much smaller, significant enhancement has also been found for oil based nanofluids [2-6]. Thermal conductivity enhancement generally follows Maxwell's effective medium theory (EMT), but some studies have shown results that far surpass those predicted by EMT [7-8]. Several mechanisms have been proposed to explain the unusual enhancements, including Brownian motion, the interfacial layer model, and particle agglomeration, but no conclusive evidence has been found and the topic remains widely debated.

The present study will examine the feasibility of copper nanoparticles dispersed in a Therminol 66 (TH66) oil as base fluid for use in thermal oil heaters. TH 66 is a widely used and readily available, high temperature liquid phase heat transfer fluid. It is a modified terphenyl heat transfer oil with stability up to $345^{\circ} \mathrm{C}$ and provides excellent fouling resistance. Copper nanoparticles were chosen mainly due to their high thermal conductivity. Singh et al. showed that with the use of surfactants, copper nanoparticle suspensions in TH66 were stable [4]. Furthermore, Timofeeva et al. showed stable concentrations of up to 7\% for a TH66 nanofluid [3]. Published correlations and data will be used to evaluate any increase in heat transfer rates, but also any drawbacks, including increased pumping power and erosion.

\section{THERMOPHYSICAL PROPERTIES OF NANOFLUIDS}

In order to assess the improvements in convective heat transfer given by a nanofluid, several thermophysical properties must be determined. The effective density $\rho$ of a nanofluid with particle volume fraction $\phi$ is given by the rule of mixtures [9]:

$$
\rho_{n f}=\rho_{p} \phi+\rho_{b f}(1-\phi)
$$

where the subscripts $n f, p$, and $b f$ denote nanofluid, particle, and basefluid respectively. The aforementioned subscripts will be used throughout this paper. Similarly, the effective specific 
heat capacity $c$ of a nanofluid can also be given by the rule of mixtures [9]:

$$
c_{n f}=\frac{1}{\rho_{n f}}\left[\rho_{p} c_{p} \phi+\rho_{b f} c_{b f}(1-\phi)\right]
$$

Unlike density and specific heat, thermal conductivity is a much more complicated and widely debated topic. On way is to use Maxwell's effective medium theory (EMT) to estimate the thermal conductivity $k$ of spherical nanoparticles suspended in the base fluid based on the volume fraction as follows [10]:

$$
\frac{k_{n f}}{k_{b f}}=1+\frac{3\left(k_{p}-k_{b f}\right) \phi}{\left(k_{p}+2 k_{b f}\right)-\left(k_{p}-k_{b f}\right) \phi}
$$

Hamilton and Crosser [11] introduced a modification of Maxwell's EMT which included a shape factor that accounted for the sphericity of the particles. More recently, Nan et al. [12] introduced a further modification to Maxwell's theory which included the particle geometry and the interfacial heat flow resistance. For spherical particles and negligible interfacial resistance, both the Hamilton and Crosser and the Nan et al. models reduce to equation (3). Although some studies have shown abnormal enhancements of thermal conductivity [7-8], a review by Buongiorno et al. [13] showed that EMT accurately predicts the thermal conductivity of a nanofluid. The model proposed by Nan et al. was shown to be accurate for nanofluids within a narrow band of $\pm 10 \%$ when compared to a wide range of published data.

Finally, particle suspensions cause an increase in the viscosity of a fluid. An analytical solution for effective viscosity $\mu$ of a solid-fluid suspension is given by Einstein's expression [14]:

$$
\mu_{n f}=\mu_{b f}(1+2.5 \phi)
$$

At the low concentrations typical of nanofluids, equation (4) results in values very close to $\mu_{\mathrm{bf}}$ which contributes to an underestimation of the viscosity at low concentrations. Furthermore, experimental data suggests that the effective viscosity of a nanofluid is significantly higher than the base fluid, and higher than the results suggested by equation (4). Unfortunately, no general correlations exist for the viscosity of a nanofluid as they depend on the shape and material of nanoparticles. Empirical correlations exist but must be derived from a specific set of data pertaining to the base fluid and nanoparticle used. Aberoumand et al. [15] derived the following equation for the viscosity of a heat transfer oil based nanofluid using experimental data:

$$
\mu_{n f}=\mu_{b f}\left(1.15+1.061 \phi-0.5442 \phi^{2}+0.1181 \phi^{3}\right)
$$

It is important to note that equation (5) may provide an overestimation of the nanofluid viscosity. As the concentration goes to zero, $\mu_{\mathrm{nf}}$ will approach $1.15 \mu_{\mathrm{bf}}$. This may result in an overestimation of the viscosity at low concentrations. Due to the minimal research done on oil based nanofluids, and experimental results for a $\mathrm{Cu}$-TH66 nanofluid only existing up to $120^{\circ} \mathrm{C}$ [4], equation (5) will be used as an approximation. To not skew results, equation (5) will be used as an upper bound, and equation (4) will be used as a lower bound for viscosity.

\section{Mathematical Model}

To assess the feasibility of nanofluids for use in a thermal oil heater, a mathematical model will be proposed in this section. Two main factors will be evaluated to determine if nanofluids are feasible for use in a thermal oil heater; the heat transfer coefficient (HTC) $h$ and the pumping power $P$. For single phase forced convection, the heat transfer coefficient will effectively show the heat transfer capability of the fluid. Although the nanofluid will have an increased thermal conductivity and specific heat capacity, which contribute to an increased HTC, a nanofluid will also have an increased viscosity, which will require an increase in pumping power to attain the same heat transfer. Therefore, both the HTC and pumping power required will need to be evaluated. There are two ways to compare single phase forced convection heat transfer; constant fluid velocity and constant pumping power. For the purposes of this work, constant fluid velocity will be used to simplify the model.

\section{A. Heat Transfer Coefficient}

A review by Prahbat et al. [17] concluded that nanofluids achieved no real enhancement of the HTC other than that caused by the augmentation of the thermal conductivity and the increase in viscosity. Prahbat et al. found that studies that showed an abnormal increase in HTC, defined their Reynolds number $R e$ in terms of the viscosity of the nanofluid at room temperature. When Reynolds number calculations were done using temperature dependent properties, the heat transfer coefficient matched those given by the Dittus Boelter correlations, within uncertainties.

Williams et al. [16] examined the turbulent convective heat transfer behavior of alumina and zirconia water based nanofluids. It was shown that if temperature dependent viscosities and thermal conductivities were used when calculating Reynolds, Prandtl, and Nusselt numbers, the Dittus Boelter correlations reproduced the convective HTC measured in the study. Therefore, the Dittus Boelter correlation for heating (equation (6)) will be used to evaluate the internal heat transfer coefficient of the thermal oil heater.

$$
h=0.023 \operatorname{Re}^{0.8} \operatorname{Pr}^{0.4}
$$

\section{B. Pumping Power}

Although the addition of nanoparticles will increase the thermal conductivity of a fluid, the added particles will also increase the viscosity of the fluid. If the viscosity increase is 
too great, the increase in pumping power may counteract the added heat transfer benefits of the nanofluid.

For a circular pipe of diameter $d$ and length $L$, and a turbulent internal flow with velocity $V$, the pumping power required is given by the following equation:

$$
P=Q \Delta p=\frac{\pi d^{4} V}{4} \frac{2 f V^{2} L}{d}
$$

where $f$ is the friction factor within the pipe. The above equation assumes that all pressure losses are given by major frictional losses. For heating, the friction factor is given by the Blasius equation:

$$
f=0.0791 R e^{-0.25}
$$

\section{Figure of Merit}

In order to assess the effectiveness of a nanofluid as a heat transfer fluid, a figure of merit (FOM) will be used to compare the performance of a nanofluid to the basefluid at various compositions and temperatures. The heat transfer coefficient (HTC) ratio will show the increase in $h$ for a nanofluid.

$$
\frac{h_{n f}}{h_{b f}}=\left(\frac{\rho_{n f}}{\rho_{b f}}\right)^{0.8}\left(\frac{c_{p n f}}{c_{p b f}}\right)^{0.4}\left(\frac{\mu_{n f}}{\mu_{b f}}\right)^{-0.4}\left(\frac{k_{n f}}{k_{b f}}\right)^{0.6}
$$

Although the HTC ratio will show an increase in heat transfer rate for a given fluid, the increased viscosity of the nanofluid can have adverse effects. The increased viscosity will increase the pumping power needed to maintain the same fluid velocity, thus decreasing the overall efficiency of the system. A simple figure of merit proposed by $\mathrm{Yu}$ et al. [18] compares the increase in heat transfer of a nanofluid to the basefluid, while accounting for pumping power.

$$
F O M=\left(\frac{h_{n f}}{h_{b f}}\right)\left(\frac{P_{b f}}{P_{n f}}\right)
$$

Substituting equations (6), (7), and (8) into equation (10) gives:

$$
F O M=\left(\frac{\rho_{n f}}{\rho_{b f}}\right)^{\frac{32}{55}}\left(\frac{c_{p n f}}{c_{p b f}}\right)^{\frac{2}{5}}\left(\frac{\mu_{n f}}{\mu_{b f}}\right)^{-\frac{26}{55}}\left(\frac{k_{n f}}{k_{b f}}\right)^{\frac{3}{5}}
$$

A FOM larger than 1 indicates a nanofluid that will have better overall heat transfer performance than the basefluid, and the higher the FOM, the better the nanofluid will perform as a heat transfer fluid.

\section{RESUlTS AND DISCUSSION}

In order to assess the performance of a $\mathrm{Cu}$-TH66 as a nanofluid, two methods were considered while using the FOM presented in equation (11):

- Varying concentration phi at a constant temperature. A temperature of $300{ }^{\circ} \mathrm{C}$ was chosen as it gives a reasonable representation of a practical thermal oil heater operating temperature.

- Varying temperature at a constant concentration phi. A range of $0-6 \%$ was used to give a large cross section of data while staying within the stable range shown by Timofeeva et al. [3].

Thermophysical properties of TH66 were obtained from the manufacturer [19]. Figure 1 shows the increase in the FOM with increasing concentration. The higher viscosity estimated by equation (5) gives a FOM that is less than 1 for low concentrations. At $\phi \approx 0.02$, the FOM becomes greater than one showing an improvement from the base fluid. This is in alignment with published experimental data. Furthermore, as equation (5) most likely overestimates the viscosity at low concentrations, the point at which the nanofluid becomes beneficial lies between the curve using Einstein's viscosity relationship and thus, will occur at a lower concentration. A maximum FOM of 1.13 and 1.15 were found at $\phi=6 \%$ using the Aberoumand and Einstein models, respectively. The curves continue to trend upward, but the question of fluid stability must be asked at higher volume fractions. Assuming the real curve lies somewhere between the two curves, a significant increase in efficiency could be obtained from the use of the TH66 $\mathrm{Cu}$ nanofluid.

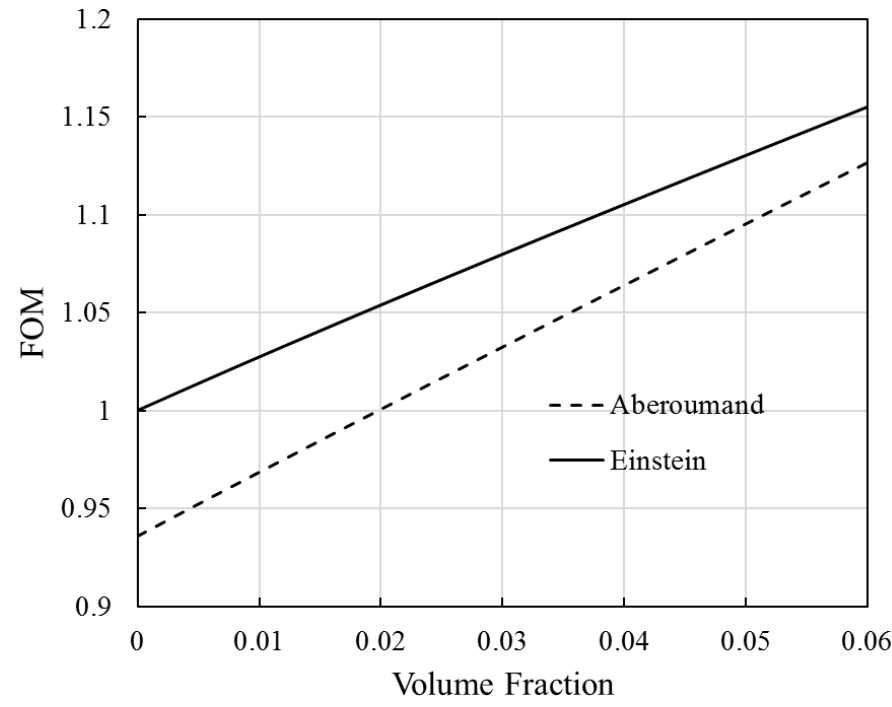

Figure 1. FOM of Cu-TH66 Nanofluid at $300^{\circ} \mathrm{C}$ with varying volume fraction

Figures 2 and 3 show the effects of increasing the temperature of the nanofluid at select volume fractions. These figures show that apart from the conservative values given by 
equation 5 for $\phi=0.01$, a FOM increase is observed for all reasonable temperatures. It is also important to note that a minimum FOM value is observed at $\mathrm{T} \approx 100-150^{\circ} \mathrm{C}$. This minimum efficiency may be important when considering inlet temperatures to a thermal oil heater.

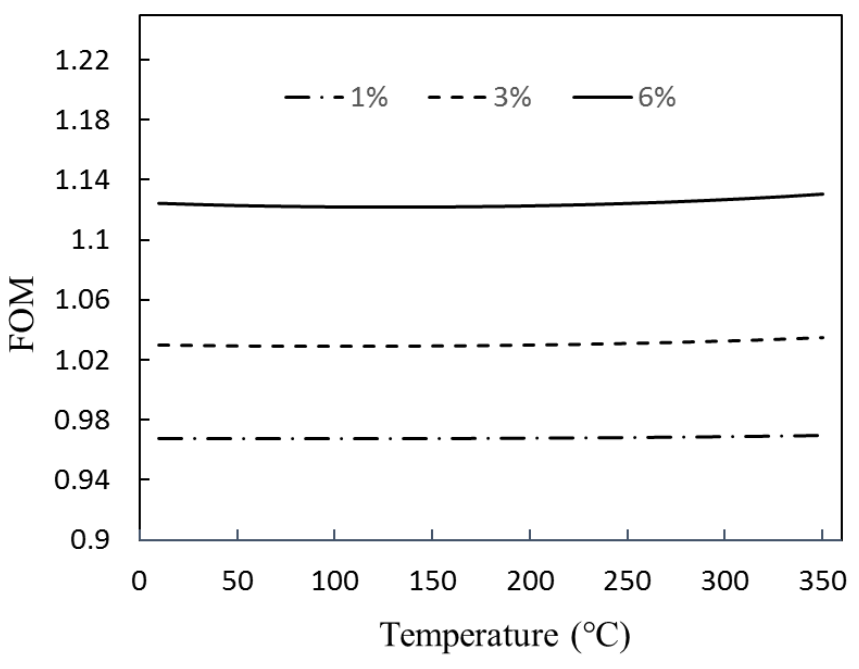

Figure 2. FOM using Aberoumand's viscosity correlation

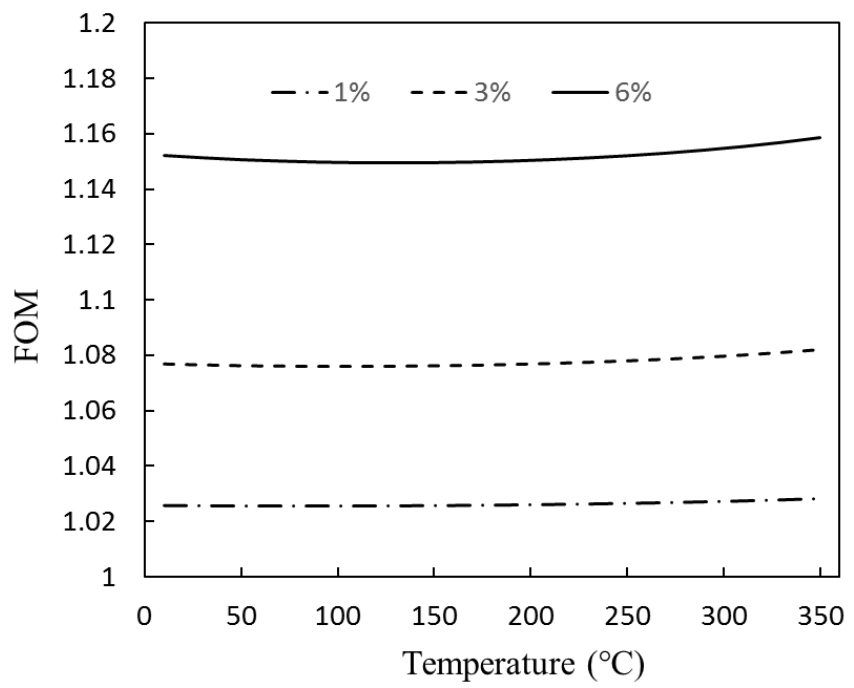

Figure 3. FOM using Einstein's viscosity correlation

In addition to the heat transfer performance increases, the nanofluid must be compatible with existing materials and not introduce unwanted corrosion or erosion effects. Molina et al. [20] tested the effects of an alumina ethylene glycol nanofluid on common cooling system materials, including aluminum and copper. Although little effects were observed on the copper specimens, there was a large surface roughness increase on the aluminum samples. Bubbico et al. [21] tested the effects of various nanofluids on many common process materials including copper, stainless steel, and aluminum. No effects were observed on the copper and stainless-steel specimens, but significant damage was caused to the aluminum specimens. It is important to note that the erosion observed was caused entirely by chemical corrosion due to the $\mathrm{pH}$ of the nanofluids rather than mechanical erosion.

It was also noted in the study that increased viscosity of the nanofluid caused pump failures. A separate test conducted by Routbort et al. [22] similarly showed effects on the pump system. In a process environment, it will be important to make sure that pump reliability will not be affected by the nanofluid. Increased pump capacity may also need to be considered to account for the increased nanofluid viscosity.

\section{RECOMMENDATIONS AND CONCLUSIONS}

From the above figures, it appears that it is feasible to use nanofluids in a thermal oil heater. Even with conservative values given by Aberoumand's viscosity correlation, the figure of merit (FOM) was found to be larger than 1 for all temperatures and $\phi>0.01$. In order to further assess the applicability, several further steps are needed to obtain a more precise answer:

- A more accurate viscosity relationship will be needed. Experimental viscosity data will be needed for a Cu-TH66 nanofluid to give a relationship of the accepted form $\mu_{n f}=\mu_{b f}\left[1+A \phi+B \phi^{2}\right]$, which will allow for more accurate heat transfer performance calculations.

- The FOM given in equation (11) does not directly apply to a thermal oil heater. Although equation (11) gives a reasonable idea of the overall heat transfer performance of a nanofluid, it does not accurately model a thermal oil heater; rather heat transfer for turbulent flow in a pipe. A thermal oil heater model will be required to determine the exact performance increases, but that was not the scope of the present study.

- If an accurate thermal oil heater model can be formulated, an economic analysis can be performed using exact performance increases, upgrade costs, and fluid costs.

\section{REFERENCES}

[1] S. Choi and J. Eastman, "Enhancing thermal conductivity of fluid with nanoparticles," ASME International Mechanical Engineering Congress and Exposition, vol. 66, no. January 1995, pp. 99-105, 1995.

[2] D. Li, W. Xie, and W. Fang, "Preparation and properties of copper- oilbased nanofluids," Nanoscale Research Letters, vol. 6, no. 1, p. 373, 2011.

[3] E. V. Timofeeva, M. R. Moravek, and D. Singh, "Improving the heat transfer efficiency of synthetic oil with silica nanoparticles," Journal of Colloid and Interface Science, vol. 364, no. 1, pp. 71-79, 2011.

[4] D. Singh, E. V. Timofeeva, M. R. Moravek, S. Cingarapu, W. Yu, T. Fischer, and S. Mathur, "Use of metallic nanoparticles to improve the thermophysical properties of organic heat transfer fluid used in concentrated solar power," Solar Energy, vol. 105, pp. 468 - 478, 2014.

[5] Y. Naresh, A. Dhivya, K. S. Suganthi, and K. S. Rajan, "Hightemperature thermo-physical properties of novel CuO-Therminol 55 nanofluid," Nanoscience and Nanotechnology Letters, vol. 4, no. 12, 2012

[6] W. Yu, E. V. Timofeeva, D. Singh, D. M. France, and R. K. Smith, "Investigations of heat transfer of copper in Therminol 59 nanofluids," 
International Journal of Heat and Mass Transfer, vol. 64, pp. 1196 1204, 2013.

[7] S. Murshed, K. Leong, and C. Yang, "Enhanced thermal conductivity of TiO 2-water based nanofluids," International Journal of Thermal Sciences, vol. 44, no. 4, pp. $367-373,2005$.

[8] M. Chopkar, P. K. Das, and I. Manna, "Synthesis and characterization of nanofluids for advanced heat transfer applications," Scripta Materialia, vol. 55, no. 6, pp. 549 - 552, 2006

[9] E. E. Michaelides, Nanofluidics.Cham: Springer International Publishing, 2014.

[10] J. C. Maxwell, A treatise on electricity and magnetism, vol. 1. Clarendon press, 1881.

[11] R. Hamilton and O. Crosser, "Thermal conductivity of heterogeneous two-component systems," Industrial \& Engineering chemistry fundamentals, vol. 1, no. 3, pp. 187-191, 1962.

[12] Nan, R. Birringer, D. Clarke, and H. Gleiter, "Enhancing thermal conductivity of fluids with nanoparticles," Journal of Applied Physics, vol. 364, no. 1, pp. 27-30, 2011.

[13] J. Buongiorno, D. C. Venerus, N. Prabhat, T. McKrell, J. Townsend, and R. Christianson, "A benchmark study on the thermal conductivity of nanofluids," Journal of Applied Physics, vol. 106, no. 9, 2009.

[14] Einstein, "Berichtigung zu meiner arbeit:eine neue bestimmung der molekuuu"ldimensionen ," Annalen der Physik, vol. 339, no. 3, pp. 591592, 1911.

[15] S. Aberoumand, A. Jafarimoghaddam, M. Moravej, H. Aberoumand, and K. Javaherdeh, "Experimental study on the rheological behavior of silver-heat transfer oil nanofluids and suggesting two empirical based correlations for thermal conductivity and viscosity of oil based nanofluids Applied Thermal Engineering, vol. 101, pp. 362-372, 2016.
[16] W. Williams, J. Buongiorno, and L.-W. Hu, "Experimental investigation of turbulent convective heat transfer and pressure loss of alu- mina/water and zirconia/water nanoparticle colloids (nanofluids) in horizontal tubes," Journal of Heat Transfer, vol. 130, pp. 042412-042412-7, 03 2008.

[17] N. Prabhat, J. Buongiorno, and L.-w. Hu, "Convective Heat Trans- fer Enhancement in Nanofluids: Real Anomaly or Analysis Arti- fact?," ASME/JSME 2011 8th Thermal Engineering Joint Conference, pp. T10070-T10070-10, 2011.

[18] W. Yu, D. M. France, E. V. Timofeeva, D. Singh, and J. L. Routbort, "Comparative review of turbulent heat transfer of nanofl Interna- tional Journal of Heat and Mass Transfer, vol. 55, no. 21, pp. 5380 - 5396, 2012.

[19] Therminol, Therminol 66 - High Performance Highly Stable Heat Transfer Fluid, 1998.

[20] G. J. Molina, M. Hulett, V. Soloiu, and M. Rahman, "Erosion effects of nanofluids on selected cooling-system materials," in Tribo-Corrosion: Research, Testing, and Applications, pp. 47-65, ASTM International, mar 2013.

[21] R. Bubbico, G. P. Celata, F. DAnnibale, B. Mazzarotta, and C. Menale, "Experimental analysis of corrosion and erosion phenomena on metal surfaces by nanofl Chemical Engineering Research and Design, vol. 104, pp. $605-614,2015$.

[22] J. Routbort, D. Singh, E. Timofeeva, W. Yu, and R. Smith, "Erosion of radiator materials by nanofluids," Argonne National Laboratory, Vehicle Technologies-Annual Review, 2010. 